\title{
Experimental studies on crushing behaviour of hexagonal composite tubes
}

\begin{abstract}
In this study, the effects of mandrel geometry on the crashworthiness performance of the fabric plain weave /epoxy hexagonal tubes are investigated. The energy absorption capacity of the tubes is investigated under uniaxial compression. An experimental, the crushing behaviour of composite hexagonally with aspect ratio 70 and different hexagonal angles ranging from $35^{\circ}$ to $55^{\circ}$ in $10^{\circ}$ increment under axial cashing load were considered. The influence of tube side angles on the crashworthiness of (FPWEH) tubes is determined. Compressive testing indicates that the $\left(\mathrm{H} .70 .45^{\circ}\right)$ tube provides a specific absorbed energy of $10.7(\mathrm{~kJ} / \mathrm{kg})$, as well as average crushing load, which is the best value compared with other tubes. Furthermore, the failure modes noted as the progressive failure mode, Therefore, this study suggests that FPWEH tubes could be used in several structural applications, i.e. in automotive as energy absorbers and in civil infrastructure as poles.
\end{abstract}

Keywords: hexagonal tubes, energy absorption, crushing behaviour

\author{
Volume 3 Issue I - 2017
}

\begin{abstract}
MFM Alkbir,' SB Mohamed,' SM Sapuan,' A Endut $^{3}$

'Department of Mechanical and Manufacturing Engineering, University of Putra Malaysia, Malaysia

${ }^{2}$ Department of Manufacturing Technology, Faculty of Innovative Design and Technology, University Sultan Zainal Abidin, Malaysia ${ }^{3}$ Department of Environmental Technology/Engineering, University of Sultan Zainal Abidin, Malaysia
\end{abstract}

Correspondence: MFM Alkbir, Department of Mechanical and Manufacturing Engineering, Universiti Putra Malaysia 43400 UPM, Serdang Selangor, Malaysia, Email alkbir74@yahoo.com

Received: July 03, 2017 | Published: October 04, 2017

\section{Introduction}

Investigations of crushing energy absorption are important and are expected from the point of view of safety design of passenger vehicles. In order to reduce the damage to occupants in a collision, it's necessary to understand the crushing behaviour and to enhance the energy absorbing capability of tubular structures. In passenger vehicles, the ability to absorb impact energy and be survivable for the occupant is called the "crashworthiness" of the structure. This absorption of energy is through controlled failure mechanisms and modes that enable the maintenance of a gradual decay in the load profile. $^{1-3}$

The effect of the number of layers, type of the fiber, type of the matrix and fiber orientation angles were the common features which are usually evaluated for each structure by developing the loaddisplacement and energy absorption relation. ${ }^{4-6}$

Throughout this investigation, the energy absorption capability and failure modes in a hexagonal composite tube are carried out experimentally an axial crushing load.

\section{Methodology}

The wet hand lay-up technique was used to fabricate a Fabric plain weave /epoxy hexagonal shape composite tube. Woven Fabric plain weave was passed through a resin bath, causing resin impregnation. This was followed by the appliance of wet fibre to the solid wooden spindle to create the hexagonal composite. A layer of wax coated the outer surface of the mandrel in order to make it easier to extract the hexagonal from the mandrel. Two layers of Fabric plain weave /epoxy wrapped to get a thickness of approximately $2 \mathrm{~mm}$. The fabricated tubes were concerned at room temperature for 24 hours to afford optimum stiffness and shrinkage.

\section{Discussion}

\section{Hexagonal tube with aspect ratio $\left(L / t=70\right.$ and $\left.\beta=35^{\circ}\right)$}

Figure 1, shows a typical load-displacement curves and deformation history for a hexagonal composite tube with an aspect ratio $\left(\mathrm{L} / \mathrm{t}=70\right.$ and $\left.\beta=35^{\circ}\right)$ subjected to the quasi-static compressive load. Linearity is evident during the pre-crushing stage as shown in Figure 1a \& 1b. In this stage the tube resistance reaches first and highest peak $\mathrm{Pi}=\mathrm{PH}=14.3 \mathrm{kN}$ at a displacement of $4 \mathrm{~mm}(0.05 \mathrm{~h})$ followed by a gradual decrease till it reaches the lowest load value $\mathrm{PL}=0.6 \mathrm{kN}$ at displacement $24 \mathrm{~mm}(0.32 \mathrm{~h})$. A rapid rise of the load carrying capacity was observed and reached its second peak value of $8.8 \mathrm{kN}$ at a displacement $33 \mathrm{~mm}(0.44 \mathrm{~h})$. The splaying failure mode, then, occurred as result of local buckling as shown in Figure 1c. After that, the progressive folding is dominating the post -crushing stage as clearly illustrated in Figures 1d-1f.

\section{Hexagonal tube with aspect ratio $\left(L / t=70\right.$ and $\left.\beta=45^{\circ}\right)$}

Figure 2 shows the load-displacement curves and deformation history of the hexagonal composite tube with an aspect ratio (L/ $\mathrm{t}=70$ and $\beta=45^{\circ}$ ). Initially, the load increased linearly to its first peak $\mathrm{Pi}=11.1 \mathrm{kN}$ at $1 \mathrm{~mm}(0.009 \mathrm{~h})$ displacement. Hence, the tube resistance dropped gradually to $1.5 \mathrm{kN}$ at $10 \mathrm{~mm}(0.09 \mathrm{~h})$ displacement. In this stage, the specimen is torn apart from the bottom end due to transverse crack and it is evident from (Figure 2(a)) (Figure 2(b)). The tube resistance was then recovered immediately to reach its second peak and highest peak $\mathrm{PH}=13.3 \mathrm{kN}$ at $33 \mathrm{~mm}(0.31 \mathrm{~h})$ displacement. Splaying failure mode with local buckling was initiated at the bottom end of the tube leading to a sudden drop of the load as shown in Figure 2c. A rapid rise of the load was observed following its sudden drop. Lastly, splaying failure mode dominated the post-crushing stage as clearly illustrated in Figures 2(d-f). The studies by Oshkovr et al. ${ }^{7}$ and Eshkoor et al. ${ }^{8}$ On silk/epoxy tubes showed that generally buckling (either local buckling or mid-length buckling) and hinge formation are the two main characteristics of woven silk/epoxy tubes, displaying a catastrophic failure.

\section{Hexagonal tube with aspect ratio $\left(L / t=70\right.$ and $\beta=55^{\circ}$ )}

The load-displacement curves in Figure 3, shows crushing history of the hexagonal composite tube with an aspect ratio $(\mathrm{L} / \mathrm{t}=70$ and $\beta=55^{\circ}$ ). Initially, the load rises almost linearly to its first peak 
$\mathrm{Pi}=14 \mathrm{kN}$ at $1 \mathrm{~mm}(0.009 \mathrm{~h})$. High sudden drop was then noted due to transverse crack at the middle of the tube and after the sudden drop the load-displacement curve becomes almost stable about sustained a load value of $3.1 \mathrm{kN}$ for displacement between $7 \mathrm{~mm}(0.06 \mathrm{~h})$ and $42 \mathrm{~mm}(0.4 \mathrm{~h})$ displacement as shown in Figure $3 \mathrm{a} \& \mathrm{~b}$. Few tiny drops of load later appeared, evolving a transverse crack by splitting the tube into two segments as shown in Figure $3 \mathrm{c} \& \mathrm{~d}$. The tube resistance recovered immediately to reach its highest peak load value of $14.8 \mathrm{kN}$ at $87 \mathrm{~mm}(0.82 \mathrm{~h})$ displacement. The tube finally collapsed as indicated in (Figure 3e) (Figure 3f).

A Crashworthiness parameters for hexagonal composite tube with aspect ratio $(\mathrm{L} / \mathrm{t}=70)$ and various angles is summarized in Table 1.
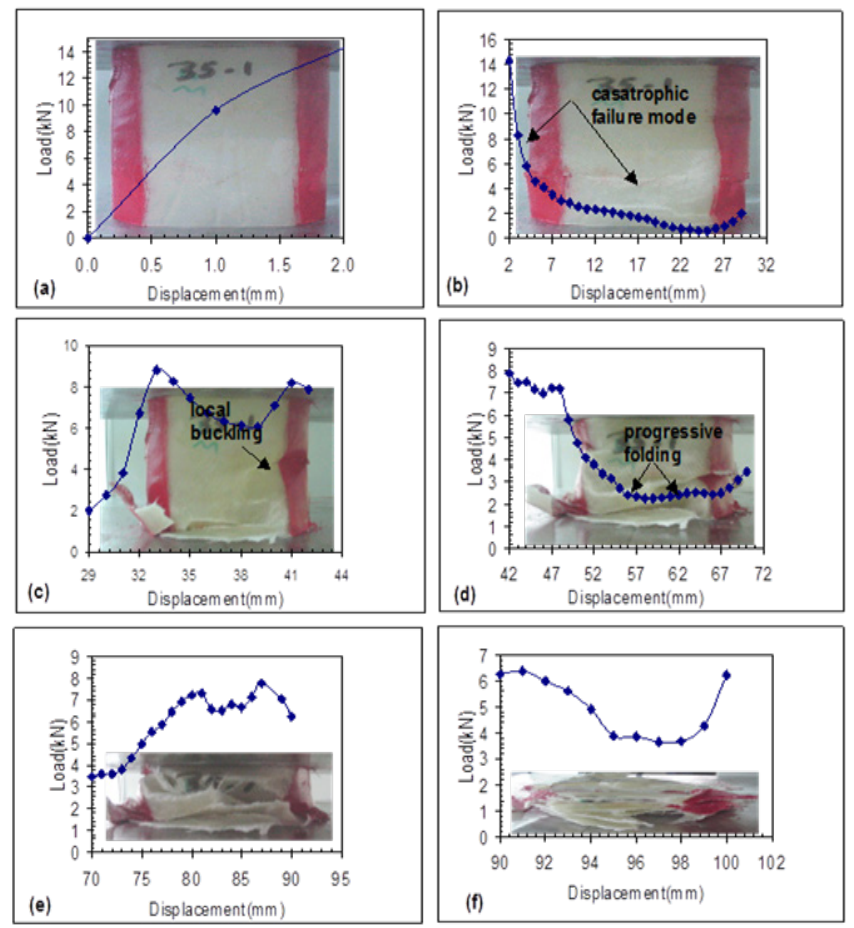

Figure I Typical load-displacement and crushing for $\left(\mathrm{H} .70 .35^{\circ}\right)$.

Table I Crashworthiness parameters for hexagonal composite tube with aspect ratio $(L / t=70)$ and various angles

\begin{tabular}{llll} 
Specimens (ID) & $\mathbf{P i}(\mathbf{k N})$ & Es (kJ/kg) & $\operatorname{Pcr}(\mathbf{k N})$ \\
\hline$\left(\mathrm{H} .70 .35^{\circ}\right)$ & 11.5 & 6.96 & $1 \mathrm{I} .5$ \\
& & & \\
$\left(\mathrm{H} .70 .45^{\circ}\right)$ & 13.2 & 10.7 & 13.2 \\
& & & \\
$\left(\mathrm{H} .70 .55^{\circ}\right)$ & 8.5 & 8.6 & 8.5
\end{tabular}


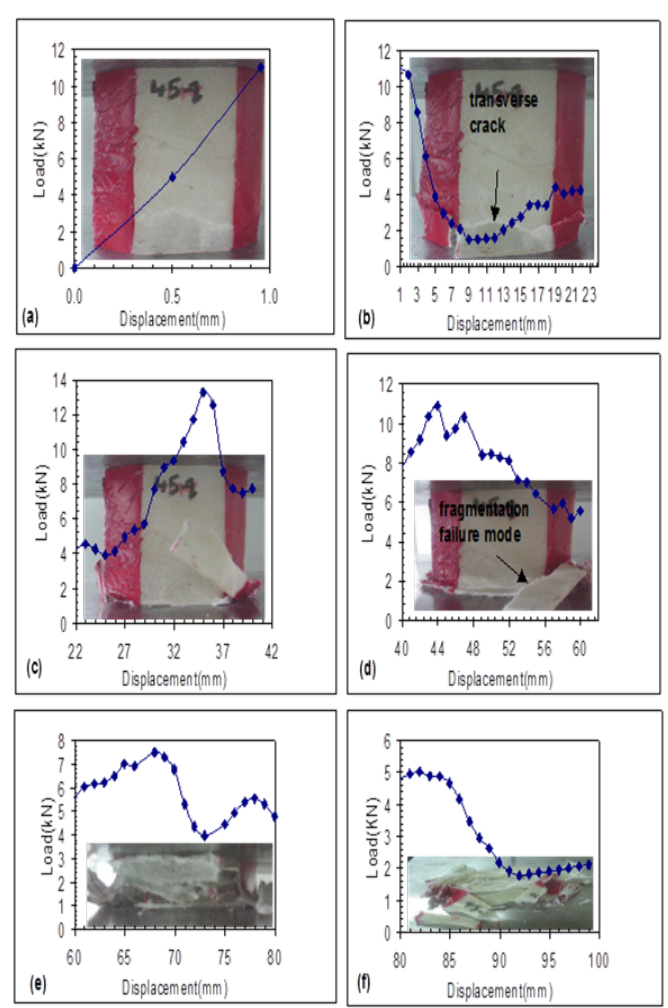

Figure 2 Typical load-displacement and crushing for $\left(\mathrm{H} .70 .45^{\circ}\right)$.
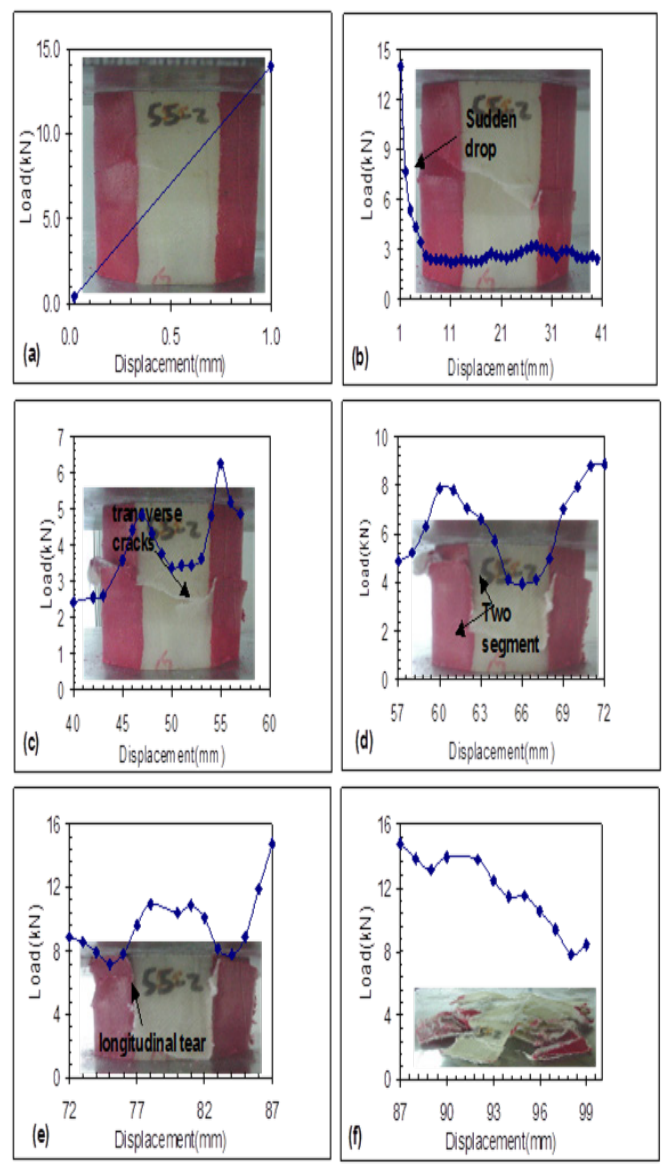

Figure 3 Typical load-displacement and crushing for $\left(\mathrm{H} .70 .55^{\circ}\right)$. 


\section{Conclusion}

The main conclusions, which can be drawn, are:

a. From the average crushing load value, it can be concluded that the average load increases as the hexagonal angle increases from $35^{\circ}$, the crush load becomes maximum at hexagonal angle $45^{\circ}$, the average crush load decreases as the hexagonal angle increases up to a hexagonal angle of $60^{\circ}$.

b. The hexagonal tube with $\beta=45^{\circ}$ exhibited the highest energy absorption capability with value angle of $35^{\circ}$ compared to the tubes with other tubes.

c. It appears that, for these models of $\mathrm{L} / \mathrm{t}=70$, a transverse crack at any section of the tube at the pre-crushing stage leads to catastrophic failure mode followed by stable load-displacement behaviour.

d. The failure of hexagonal tubes appeared as a progressive crushing type when subjected to compressive load.

\section{Acknowledgments}

The authors would like to thank University Putra Malaysia and staff for the support for this research.

\section{Conflict of interest}

There is no conflict of interest.

\section{References}

1. Elgalai AM, Mahdi E, Hamouda AMS, et al. Crushing response of composite corrugated tubes to quasi-static axial loading. Compos Struct. 2004;66(1-4):665-671.

2. Bois P Du, Chou CC, Fileta BB, et al. Vehicle and Occupant Protection. 2004. p. 304-330.

3. Alkbir MFM, Sapuan SM, Nuraini AA, et al. Fibre properties and crashworthiness parameters of natural fibre-reinforced composite structure: A literature review. Compos Struct. 2016;148:59-73.

4. Ochelski S, Gotowicki P. Experimental assessment of energy absorption capability of carbon-epoxy and glass-epoxy composites. Compos Struct. 2009;87(3):215-224.

5. Hu D, Zhang C, Ma X, et al. Effect of fiber orientation on energy absorption characteristics of glass cloth/epoxy composite tubes under axial quasi-static and impact crushing condition. Compos Part A: Applied Sci \& Manufacturing. 2016;90:489-501.

6. Humberto J, Almeida S, Ribeiro ML, et al. Damage modeling for carbon fiber/epoxy filament wound composite tubes under radial compression. Compos Struct. 2016;160:204-210.

7. Oshkovr SA, Eshkoor RA, Taher ST, et al. Crashworthiness characteristics investigation of silk/epoxy composite square tubes. Composite Structures. 2012;94(8):2337-2342.

8. Eshkoor RA, Oshkovr SA, Sulong AB, et al. Comparative research on the crashworthiness characteristics of woven natural silk/epoxy composite tubes. Materials \& Design. 2013;47:248-257. 